\title{
Desain Interior Car Body Kereta Api Komuter Khusus Wanita di Indonesia (Studi Kasus: Kereta Rel Diesel Elektrik Prambanan Ekspress)
}

\author{
Aditya Mumtaz dan Bambang Tristiyono \\ Departemen Desain Produk Industri, Fakultas Teknik Sipil dan Perencanaan, \\ Institut Teknologi Sepuluh Nopember (ITS) \\ e-mail: gacombi@prodes.its.ac.id
}

\begin{abstract}
Abstrak-Meningkatnya kepadatan penumpang pada moda transportasi berbanding lurus dengan tindak kriminalitas. Kabin penumpang khusus wanita yang terdapat pada KRL \& KRDE merupakan bentuk peningkatan layanan yang diharapkan menjadi salah satu ujung tombak dalam hal perlindungan terhadap konsumen khususnya perempuan. Kabin penumpang khusus wanita yang masih menggunakan standar kabin umum pada KRDE Prambanan Express mengakibatkan kesan feminim kurang menonjol pada interior. Kedua, atribut interior belum sesuai dengan ergonomi \& anthropometri penumpang wanita. Ketiga, LOPAS perlu disesuaikan dengan kebiasaan dan kecenderungan penumpang wanita. Keempat, perlunya penyesuaian bentuk \& sistem paneling untuk mempermudah perawatan dan produksi. Perancangan ini berfokus pada redesain kabin penumpang khusus wanita di KRDE Prambanan Express, meliputi penambahan sign, recolour, dan penambahan utilitas untuk menonjolkan kesan feminim. Kedua, pembuatan atribut interior sesuai ergonomi dan anthropometri penumpang wanita. Ketiga, penyesuaian LOPAS dengan kebiasaan dan kecenderungan penumpang wanita sehingga tidak menimbulkan penumpukan. Keempat, implementasi sistem modular agar kabin menjadi mudah perawatan \& produksinya.
\end{abstract}

Kata kunci: modular, car body, feminin, KRL

Abstract-the increase passengers of public transportation are equal compared with the crime act. Because of that, the woman passenger cabin on KRL and KRDR was built by KAI to protect them. This cabin is still use a regular cabin standard of KRDE Express. It makes the interior cabin looks basic. Also, the cabin are not yet using an ergonomic and anthropometric study, and it need and adjustment and a panelling system to make it easier to care. This design are focusing on redesign the woman passenger's cabin on KRDE Prambanan Express, including the addition of sign, recolor and the addition of new utilities to make it more feminine, redesigning the furniture using an woman ergonomic and anthropometric study, the adjustment between LOPAS and woman passenger's habit, and the modular system implementation on the furniture to make it cabin easier to care.

Key words: modular, car body, feminine, KRL

\section{PENDAHULUAN}

Indonesia merupakan negara berkembang dengan tingkat mobilitas penduduknya yang cukup tinggi. Hal ini dibuktikan dengan tingginya angka penggunaan sarana transportasi darat, khususnya penggunaan kereta api [1]. Kereta Api komuter adalah terobosan PT. Kereta Api Indonesia (PT. KAI) dalam menjawab kebutuhan akan transportasi umum jarak menengah yang cepat, nyaman dan ekonomis antar kota besar di Indonesia. Namun, banyaknya peminat angkutan komuter tersebut dapat menjadi bumerang bagi penumpang sendiri. Hal ini dibuktikan dengan banyaknya peristiwa saling berebut tempat duduk, hingga terjadinya pelecehan seksual ketika kereta penuh saat jam sibuk berangkat dan pulang kantor. Tentu saja kaum yang paling dirugikan dalam hal ini adalah wanita. Berdasarkan catatan Polda Metro Jaya, selama tahun 2012 ada sebanyak 31 kasus kriminal di angkutan umum yang terdiri dari 11 kasus kejahatan di taksi, 13 kasus kejahatan di angkutan kota, 2 kasus kejahatan di atas truk, 1 kasus kejahatan di bajaj dan 4 kasus kejahatan di kereta api. Dari jumlah tersebut, 16 kasus merupakan pelecehan seksual yang dialami oleh kalangan perempuan.

Dari laporan tersebut, KAI mencetuskan gerbong yang dikhususkan untuk wanita pada tahun 2012 di KRL Commuterline Jabodetabek. KAI mencontoh ide ini seperti yang telah dilakukan di negara-negara maju seperti Jepang. Dengan adanya gerbong ini diharapkan kasus pelecehan terhadap wanita di dalam komuter saat Rush Hour akan berkurang. Gerbong khusus wanita di Commuterline Jabodetabek inilah yang kemudian menjadi percontohan gerbong khusus wanita yang ada di daerah lain di Indonesia, yaitu komuter Prambanan Express yang melayani rute Yogyakarta-Surakarta.

Sesuai dengan hasil pengamatan yang dilakukan di gerbong khusus wanita di KRDE Prambanan Express problem utama yang timbul di gerbong khusus wanita ada dua yaitu dari segi teknis dan mental budaya. Secara garis besar, permasalahan yang diambil dalam perancangan ini adalah:

1. Masih terjadi banyak penumpukan penumpang di konfigurasi LOPAS lama

2. Dengan warna kuning pucat, warna interior gerbong khusus wanita kurang memberikan citra keanggunan.

3. Gerbong Prambanan Express yang dibangun tahun 1994 sebagai KRL BN-Holec memerlukan penyusunan system panel modular untuk mempermudah proses produksi dan perawatan.

4. Dimensi ukuran tempat duduk masih menggunakan presentile 50 publik

5. Tempat duduk menggunakan layout seperti gerbong umum, sehingga tidak menjawab maksimalitas ruang.

6. Storage yang kecil dan sulit dijangkau menyebabkan lebih sering tidak terpakai.

7. Minimnya sign dan pembeda antara gerbong khusus dan umum menyebabkan tujuan adanya kabin khusus wanita itu sendiri tidak terpenuhi. 


\section{METODE PENELITIAN}

A. Tahap survey mitra dan pengambilan data

Metode penggalian informasi ini dilakukan secara langsung ke tempat mitra produksi selaku tenaga ahli. Dari sesi tanya jawab dengan pihak terkait didapatkan data teknis mengenai kereta terkait. Mulai dari ukuran, kelistrikan, spesifikasi mesin, dan seluruh atribut yang ada di dalam kereta terkait yang dalam hal ini KRDE Prambanan Ekspress.

\section{B. Tahap survey aktivitas lapangan}

Metode pengumpulan data ini dilakukan langsung ke objek perancangan berada yaitu daerah operasi KRDE Prambanan Ekspress untuk mengetahui kondisi nyata di lapangan. Dari survey ini didapatkan data mengenai demografi penumpang, sikap penumpang di kereta, gaya hidup, barang bawaan, kebutuhan yang belum terpenuhi dalam kabin, produk pesaing, serta kelebihan dan kekurangan kabin penumpang yang ada sekarang.

\section{Tahap pengambilan data literatur}

Metode pengambilan data yang dilakukan dengan mengumpulkan berbagai data dari jurnal, artikel ilmiah, peraturan perundang undangan, ataupun buku. Hasil dari metode penelitian ini adalah data mengenai kebijakan yang berlaku, standarisasi rancangan, ukuran-ukuran anthropometri, material properties bahan, dan hal-hal lain mengenai proses perancangan dan analisanya [2, 3, 4, 5, 6, 7 dan 8].

\section{Tahap studi dan analisa}

Tahap studi dan analisa adalah proses pengolahan data-data yang telah didapat dari proses pengambilan data melalui survey mitra produksi, survey lapangan, dan studi literatur $[9,10,11$, 12, 13, 14 dan 15]. Proses pengolahan data ini dilakukan agar mendapatkan hasil maksimal pada rancangan yang akan dibuat [. Studi dan analisa inti dari penelitian ini adalah:

1. Analisa komponen produk dan konfigurasi untuk mendapatkan LOPAS terbaik.

2. Analisa struktur dan bahan untuk mendapatkan bahan terbaik dan paling cocok untuk desain.

3. Analisa part panel interior untuk memperoleh sistem modular yang paling efektif dan efisien dalam implementasinya.

4. Analisa bentuk dan estetika untuk mendapatkan desain interior yang paling baik dan memiliki value yang tinggi.

5. Analisa sign dan warna pemilihan sistem tanda dan skema warna interior yang paling cocok utuk kabin wanita.

6. Analisa ekonomi dan bisnis menentukan rencana bisnis hasil perancangan ke depannya.

\section{HASIL DAN PEMBAHASAN}

\section{A. Objective tree}

Objective tree adalah detail dari brainstorm brief idea. Cabang terakhir dari brief ddea yang dikembangkan pada objective tree adalah new image dan modular panel (Gambar 1).

Kesimpulan dari objective tree adalah desain terbagi menjadi part, modul, dan menggunakan joint screw atau bolt. Serta implementasi anthropometri perempuan, penambahan signage, desain minimalis, dan warna pastel untuk new image interior.

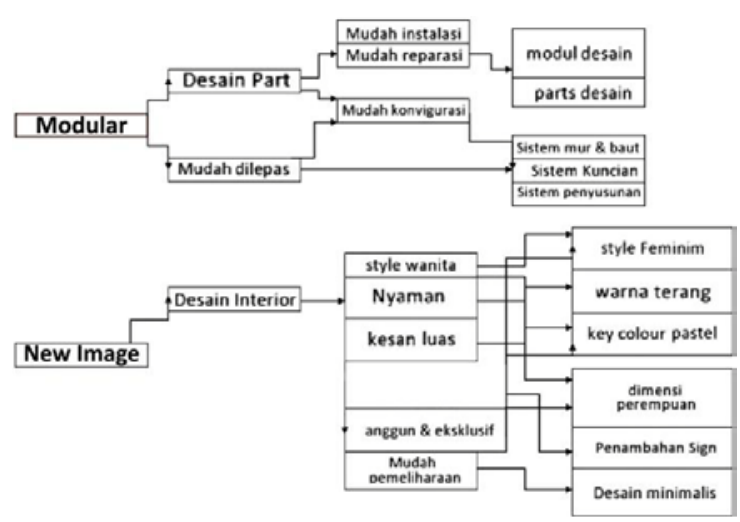

Gambar 1. Objective tree

\section{B. Mood board}

Mood board adalah tema utama yang diambil untuk arah pengembangan (Gambar 2). Keyword mood board ini didapat dari simpulan objective tree.

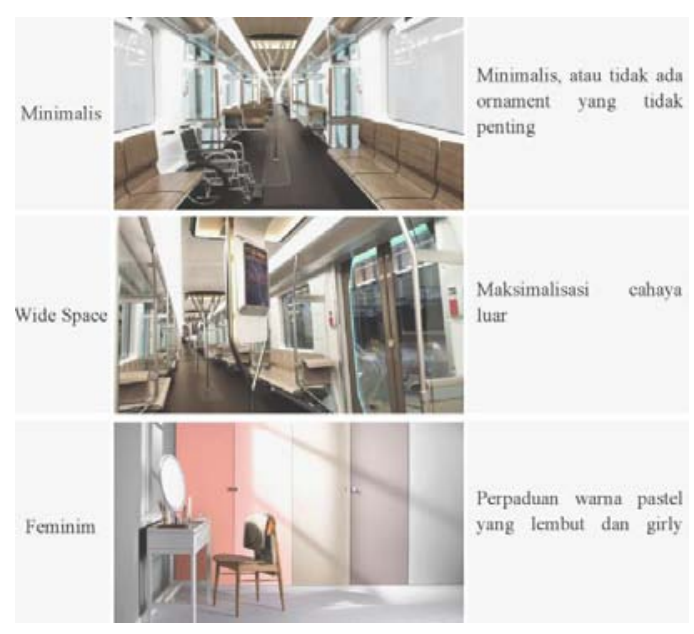

Gambar 2. Mood board

Beberapa kesimpulan dari mood board adalah bahwa desain kabin baru mengacu pada konsep minimalis, wide space, dan feminine. Penjelasannya adalah sebagai berikut:

1. Minimalis, desain sedikit terdapat atribut-atribut yang kurang penting, dan minim ornamen. Penggunaan style minimalis akan mempermudah perawatan dan menghemat biaya produksi.

2. Wide Space, penggunaan warna dasar putih sehingga memberi kesan luas pada ruangan.

3. Feminine, penggunaan atribut interior yang memiliki karakteristik perempuan. Atribut desain yang berkarakteristik perempuan adalah memiliki banyak karakter lengkung dan memiliki warna cerah serta lembut seperti warna pastel.

\section{Styling board}

Styling board adalah arah style pengembangan interior. Ditinjau dari 2 buah kutub berlawanan dalam sebuah koordinat. Gambar 2 menjelaskan konsep styling board desain interior kereta ini. 


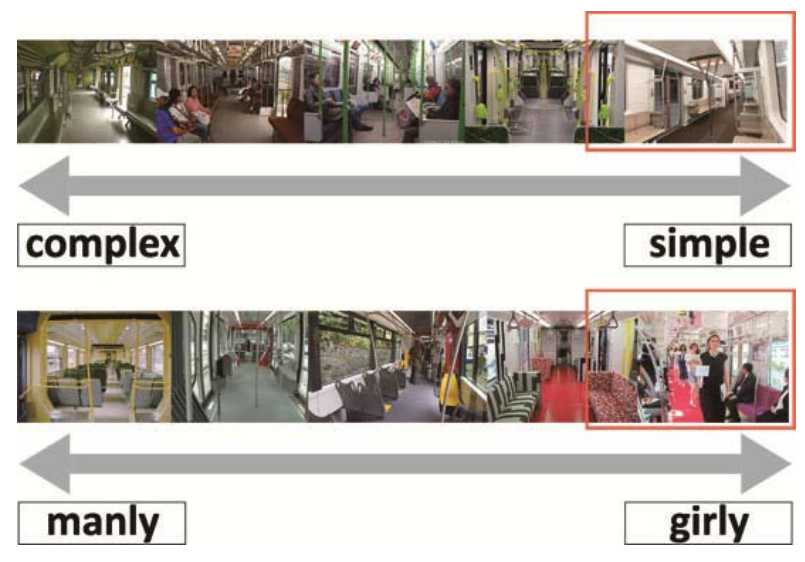

Gambar 3. Styling board

Konsep desain yang didapat diambil dari analisa permasalahan di objective tree dan dari analisa karakter desain di mood board dan styling board adalah:

1. Pastel key color, penggunaan warna pastel.

2. Simplicity, tidak terlalu banyak utility yang kurang penting.

3. Clean, tidak terlalu banyak atribut interior.

4. Wide space, memberi kesan luas dengan pemanfaatan kaca dan warna putih.

5. Curves, memudahkan perawatan, produksi, dan memberi kesan wanita.

6. Modular, desain panel terdiri dari modul untuk mempermudah produksi dan perawatan.

\section{Analisa Konfigurasi LOPAS (Load of Passanger)}

1. Alternatif 1

Menampung 110 orang yang terdiri dari 54 passenger chair, 44 adjustable seat, 10 berdiri, 2 priority seat (Gambar 4).

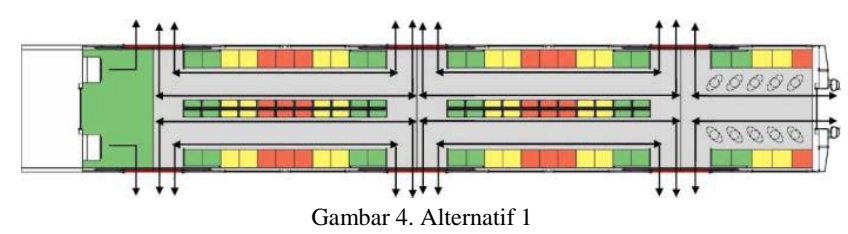

2. Alternatif 2

Menampung 102 orang yang terdiri dari 48 passanger chair, 2 priority chair, dan 58 berdiri (Gambar 5 ).

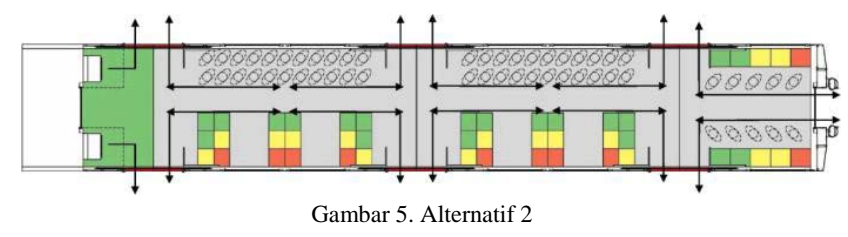

3. Alternatif 3

Menampung 150 orang yang terdiri dari 148 leaning chair dan 2 priority chair (Gambar 6).

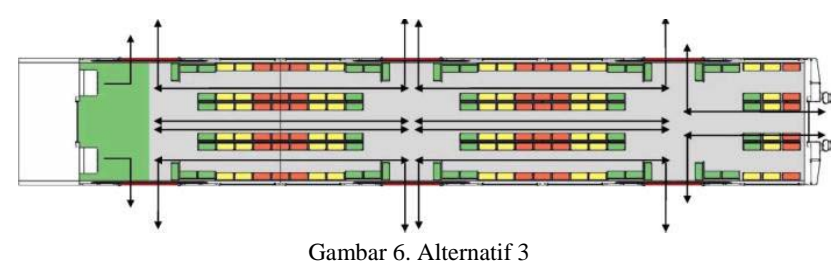

Dari ketiga alternatif LOPAS yang telah dibuat, peneliti melakukan metode scoring dengan hasil dapat dilihat pada Tabel 1.
Tabel 1. Matriks Penilaian Load of Passenger (LOPAS)

\begin{tabular}{|l|c|c|c|c|c|c|}
\hline & \multicolumn{2}{|c|}{ ALT 1 } & \multicolumn{2}{c|}{ ALT 2 } & \multicolumn{2}{c|}{ ALT 3 } \\
\hline PARAMETER(K) & RAT & SCO & RAT & SCO & RAT & SCO \\
\hline Sirkulasi(0,2) & 4 & 0,8 & 4 & 0,8 & 2 & 0,4 \\
\hline Penumpang(0,3) & 4 & 1,2 & 4 & 1.2 & 5 & 1,5 \\
\hline Jangkauan(0,1) & 4 & 0,4 & 4 & 0.4 & 2 & 0.2 \\
\hline Clearance(0,1) & 4 & 0.4 & 4 & 0.4 & 2 & 0.2 \\
\hline Comfort(0,3) & 5 & 1.5 & 3 & 0.9 & 2 & 0.6 \\
\hline TOTAL & & 4.3 & & 3.7 & & 2.9 \\
\hline
\end{tabular}

Kesimpulannya adalah alternatif 1 merupakan LOPAS yang terpilih ditinjau dari kenyamanan sarana duduk, kelengkapan fitur, dan daya tampung penumpang.

\section{E. Analisa Modular Panel}

Sesuai dengan batasan bahwa desain baru tidak boleh mengubah stuktur rangka desain lama, maka dari pembagian panjang badan kereta, panel interior dapat dibagi menjadi 11 bagian modul. Tiap modul memiliki lebar 1650 mm (Gambar 7).
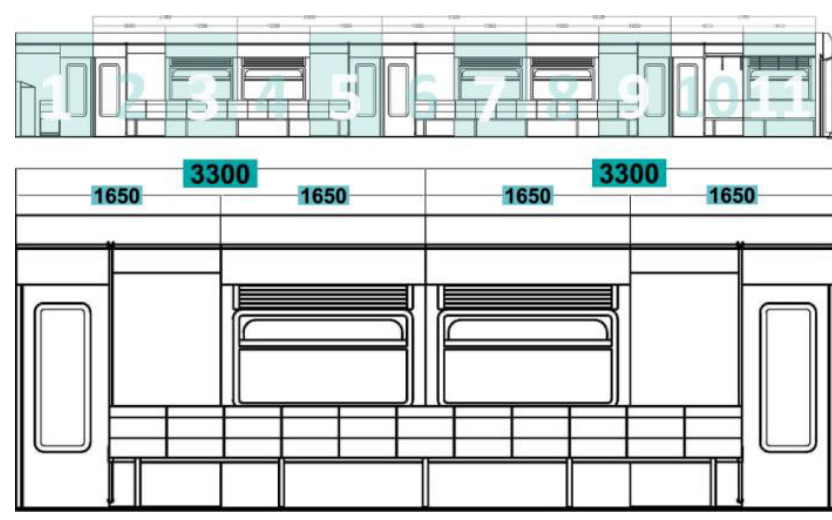

Gambar 7. Pembagian dan ukuran modul

Terdapat 7 jenis panel penyusun dinding kabin kereta. Gambar 8 menunjukkan posisi instalasi panel pada rangka kereta.

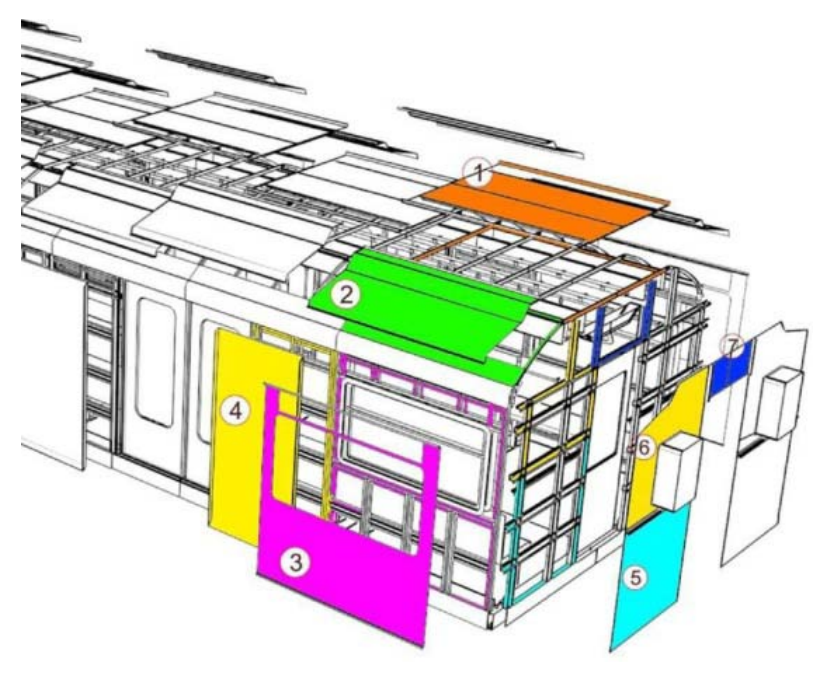

Gambar 8.Posisi instalasi panel

Joint yang digunakan untuk instalasi panel pada rangka adalah screw. Penggunaan screw dinilai paling efektif dan efisien karena murah, mudah lepas-pasang, dan cukup kuat. 


\section{F. Analisa cross section}

Secara garis besar terdapat 3 cross section utama di dalam rancangan ini. Section 1 adalah area prioritas untuk lansia dan difabel, section 2 untuk penumpang umum duduk, dan section 3 untuk penumpang duduk dan berdiri (Gambar-gambar 9, 10 dan 11). Dimensi setiap section dapat dilihat pada Tabel-tabel 2, 3 dan 4.

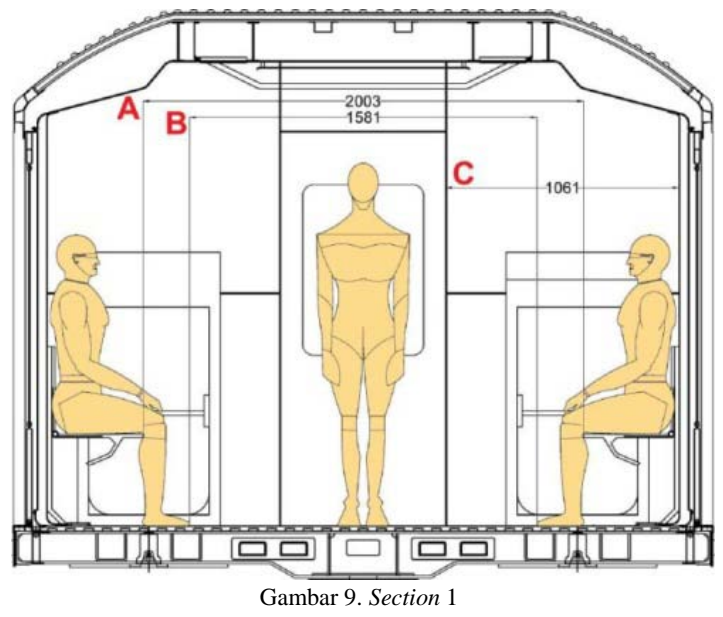

Tabel 2. Dimensi Section 1

\begin{tabular}{|c|c|c|c|}
\hline Kode & Keterangan & Persentile & Hasil \\
\hline$A$ & Lebar ruang antar temopat duduk & Wanita, 50 & $2003 \mathrm{~mm}$ \\
\hline$B$ & $\begin{array}{c}\text { Lebar ruang antar kursi saat } \\
\text { operasional }\end{array}$ & Wanita, 50 & $1581 \mathrm{~mm}$ \\
\hline$C$ & Lebar Zona Prioritas & Wanita, 50 & $1061 \mathrm{~mm}$ \\
\hline
\end{tabular}

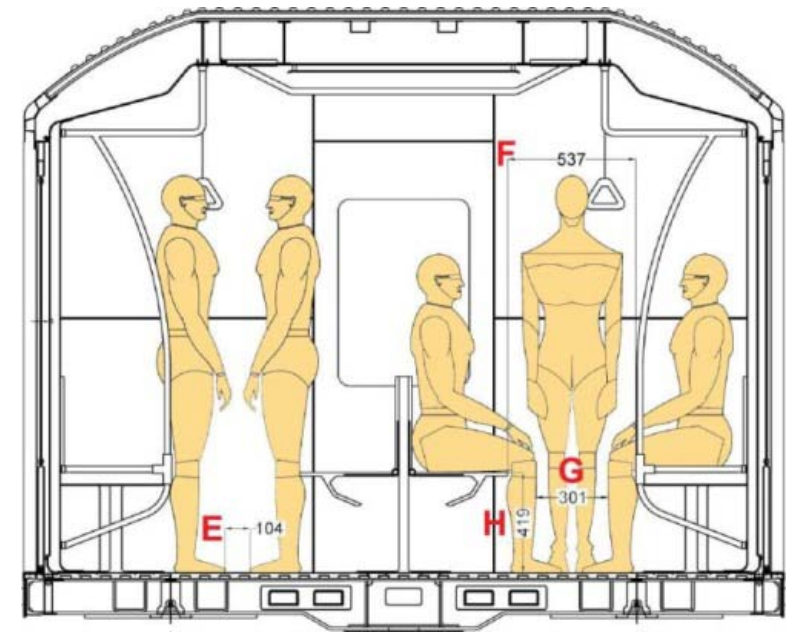

Gambar 10. Section 2

Tabel3.Dimensi Section 2

\begin{tabular}{|c|c|c|c|}
\hline Kode & Keterangan & Persentile & Hasil \\
\hline$E$ & $\begin{array}{c}\text { Clearance antar penumpang saat } \\
\text { kondisi Adjustable chair terbuka }\end{array}$ & Wanita, 50 & $104 \mathrm{~mm}$ \\
\hline$F$ & $\begin{array}{c}\text { Lebar ruang antar kursi konvensional } \\
\text { dan adjustable chair saat terbuka }\end{array}$ & Wanita, 50 & $537 \mathrm{~mm}$ \\
\hline$G$ & $\begin{array}{c}\text { Lebar space akomodasi saat adjustable } \\
\text { chair di gunakan }\end{array}$ & Wanita, 50 & $301 \mathrm{~mm}$ \\
\hline$H$ & Tinggi kursi dari lantai & Wanita, 50 & $419 \mathrm{~mm}$ \\
\hline
\end{tabular}

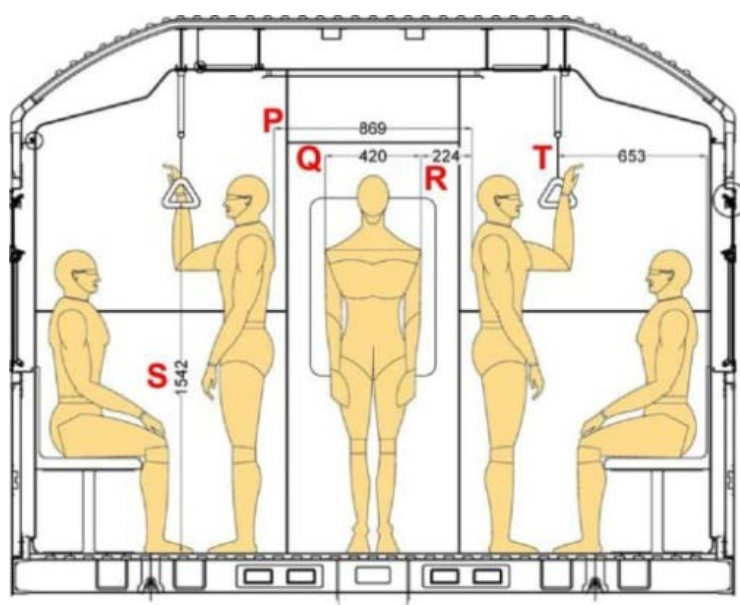

Gambar 11. Section 3

Tabel 4. Dimensi Section 3

\begin{tabular}{|c|c|c|c|}
\hline Kode & Keterangan & Persentile & Hasil \\
\hline$P$ & $\begin{array}{c}\text { Lebar ruang antar penumpang di zona } \\
\text { berdiri }\end{array}$ & Wanita, 50 & $869 \mathrm{~mm}$ \\
\hline$Q$ & Lebar bahu wanita & Wanita, 50 & $420 \mathrm{~mm}$ \\
\hline$R$ & $\begin{array}{c}\text { Clearence antara penumpang berdiri } \\
\text { dengan penumpang zona sirkulasi }\end{array}$ & Wanita, 50 & $224 \mathrm{~mm}$ \\
\hline$S$ & Tinggi jangkauan Hand Grip dari lantai & Wanita, 50 & $1542 \mathrm{~mm}$ \\
\hline$T$ & $\begin{array}{c}\text { Lebar zona antara tempat duduk dan } \\
\text { Hand Grip }\end{array}$ & Wanita, 50 & $653 \mathrm{~mm}$ \\
\hline
\end{tabular}

\section{G. Eksplorasi Sketsa Desain}

Eksplorasi desain kereta api dapat dilihat pada Gambar 12.

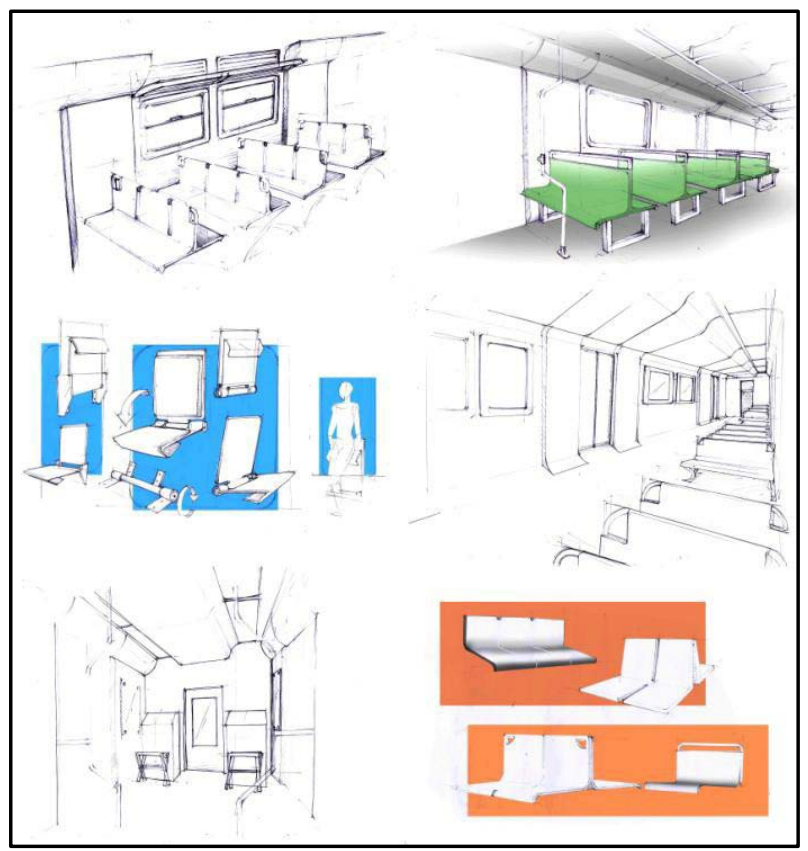

Gambar 12. Sketsa Eksplorasi Desain

\section{H. Alternatif Desain}

Alternatif desain kereta api dapat dilihat pada Gambar-gambar 13, 14 dan 15. Tabel 5 menjelaskan analisa pemilihan alternatif desain. 


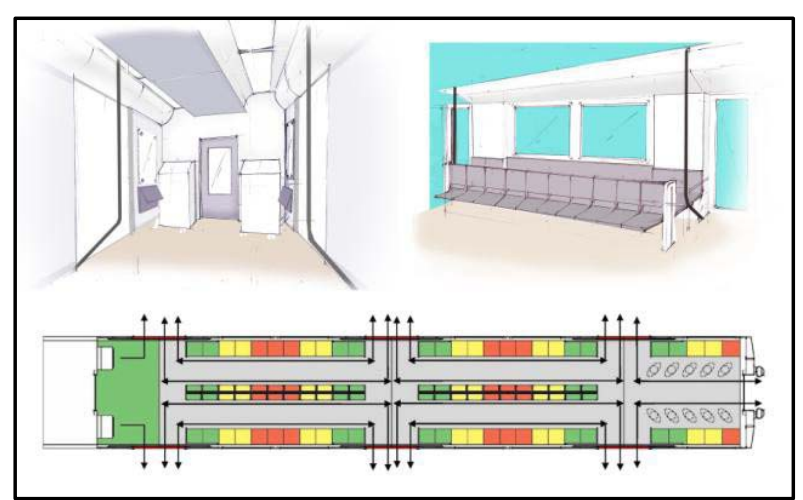

Gambar 13. Alternatif 1

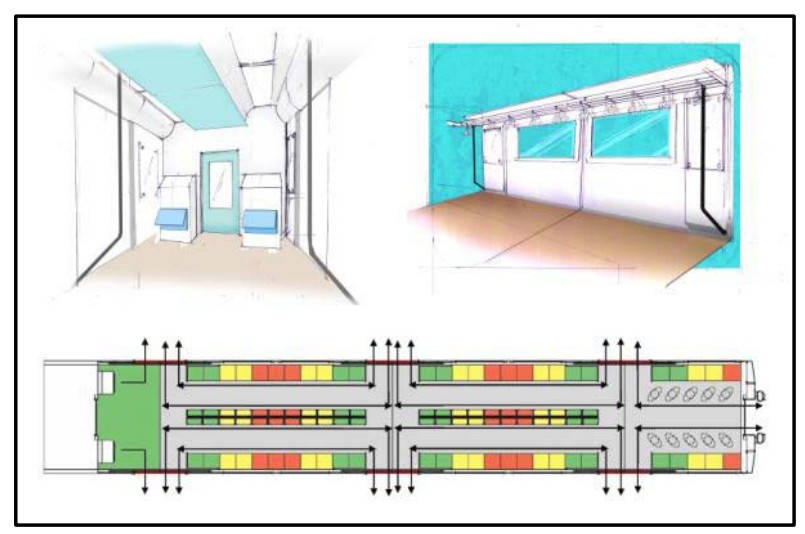

Gambar 14. Alternatif 2

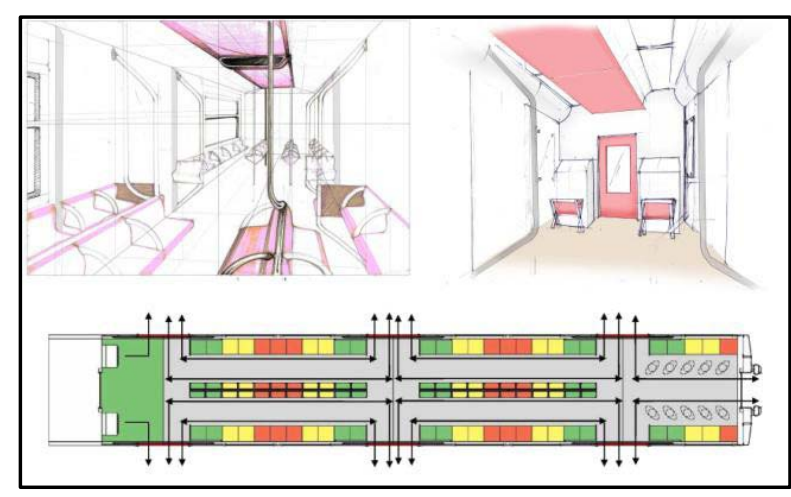

Gambar 15. Alternatif 3

Tabel 5.Matriks Penilaian Alternatif Desain

\begin{tabular}{|l|c|c|c|c|c|c|}
\hline & \multicolumn{2}{|c|}{ ALT1 } & \multicolumn{2}{c|}{ ALT2 } & \multicolumn{2}{c|}{ ALT3 } \\
\hline PARAMETER (K) & RAT & SCO & RAT & SCO & RAT & SCO \\
\hline Estetika(0,3) & 5 & 1.5 & 3 & 0.9 & 2 & 0.6 \\
\hline Utilitas(0,3) & 4 & 1,2 & 4 & 1.2 & 5 & 1,5 \\
\hline Clearance(0,1) & 4 & 0.4 & 4 & 0.4 & 2 & 0.2 \\
\hline Jangkauan(0,1) & 4 & 0,4 & 4 & 0.4 & 2 & 0.2 \\
\hline Sirkulasi(0,2) & 4 & 0,8 & 4 & 0,8 & 2 & 0,4 \\
\hline \multicolumn{1}{|c|}{ TOTAL } & & 4.3 & & 3.7 & & 2.9 \\
\hline
\end{tabular}

Kesimpulannya, Alternatif 1 terpilih karena memiliki nilai estetika, utilitas dan sirkulasi yang paling bagus.

\section{Pengembangan dengan 3D Modelling}

Terdapat 3 section dalam desain final interior produk pengembangan dari alternatif desain 1 (Gambar-gambar 16, 17 dan 18).

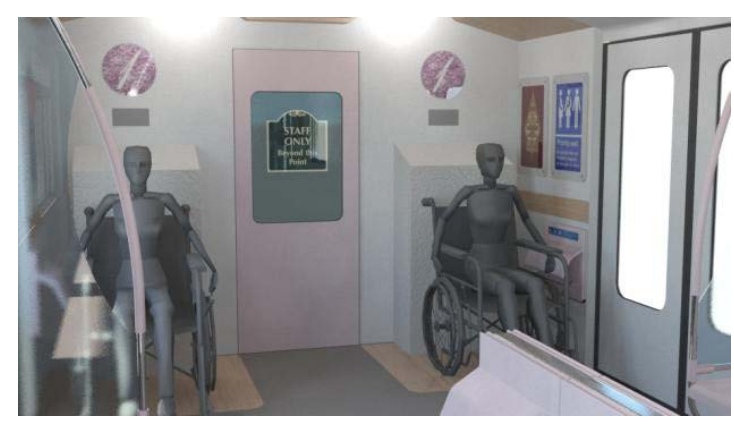

Gambar.16.Section1: area prioritas untuk difabel

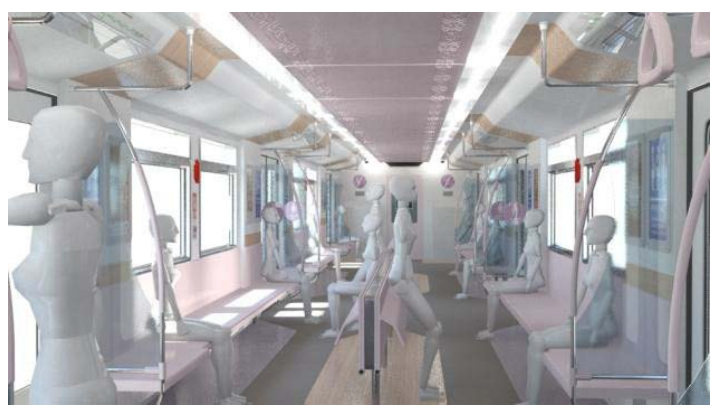

Gambar 17. Section 2: area publik duduk dan adjustable seat

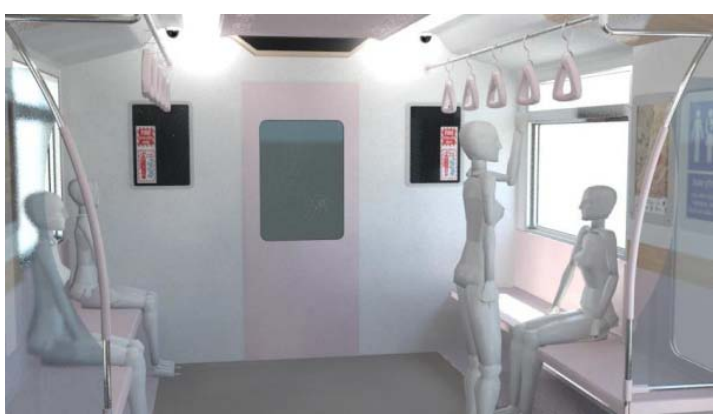

Gambar 18. Section 3: fasilitas duduk dan berdiri

Gambar 19 menunjukkan studi model produk interior kereta api dengan skala 1:8.

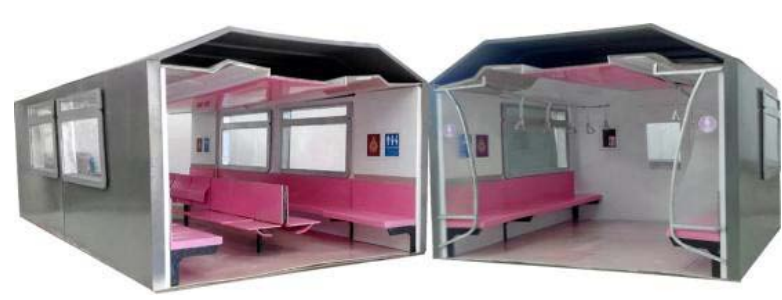

Gambar 19. Studi model 1:8

\section{KESIMPULAN}

Kesimpulan dari proses perancangan interior car body kabin khusus wanita studi kasus KRDE Prambanan Express yang telah penulis lakukan adalah:

1. Implementasi $L O P A S$ baru dengan adanya adjustable seat di tengah sebagai upaya peningkatan fasilitas sekaligus upaya preventif menertibkan penumpang.

2. Menggunakan desain bertema feminim, minimalis, clean, simple, wide space, dipadu dengan bright-pastel pallette colour untuk mendapatkan kesan wanita, luas, dan modern dalam interior kabin baru. 
3. Penggunaan sistem paneling pada interior kabin sebagai upaya standarisasi tipe kereta sejenis, sehingga biaya pembuatan parts dan perawatan dapat lebih hemat. Ukuran lebar panel adalah 1650, dengan jumlah total 11 set.

4. Penggunaan persentile 50 wanita untuk ukuran dan jangkauan pada kursi atau elemen interior lain yang ada.

5. Penambahan adjustable seat yang bisa diubah dari tempat duduk konvensional menjadi leaning chair, dan sebaliknya (Gambar 20).

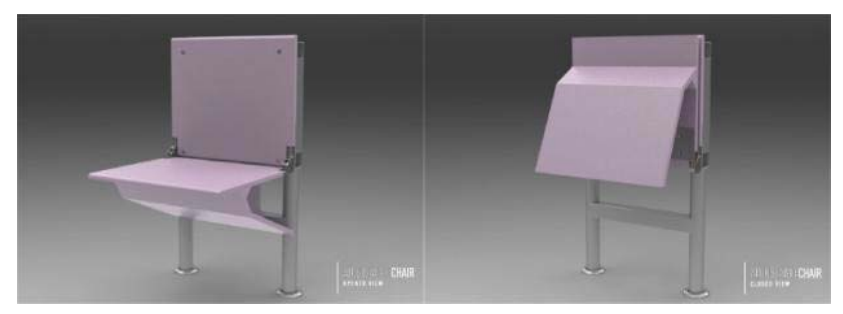

Gambar 20. Adjustable sea

6. Penambahan zona prioritas khusus untuk lansia dan difabel di section 1, penambahan partisi, signage dan zoning lantai.

Sedangkan saran yang penulis ingin sampaikan adalah sebagai berikut:

1. Untuk peningkatan value car body, disarankan untuk menggunakan sistem modular panel agar mempermudah proses produksi dan perawatan, disertai dengan penambahan fasilitas yang sesuai dengan standar peraturan yang ada.

2. Penggantian sistem ticketing dari tanpa tempat duduk menjadi bernomor tempat duduk dengan pembedaan harga baru.

\section{DAFTAR PUSTAKA}

[1] Badan Pusat Statistik. 2014. Data Penumpang Kereta Api. Diakses 15 Juni 2014 pada situs: https://www.bps.go.id/linkTabelStatis/view/id/1417

[2] Arfianto, M.R. (2013). Analisis Konsumsi Daya pada Gerbong Kereta Api Penumpang Kelas Eksekutif, Bisnis, dan Ekonomi. Digital Library UNDIP.

[3] Azu.(2010). Soalan Mesin KRDI \& KRD MCW 301-302. Diakses 14 Juli 2015, dari Semboyan 35: http://www.semboyan35.com/showthread.php?tid=4143

[4] Fayyadl, M. (2012). Analisis Kebisingan Kereta Api Prambanan Ekspress. Digital Library UNS.

[5] Hendra, A. (2013). Desain KRL Jabodetabek Dengan Konsep Fresh, Clean. Digital Library ITS.

[6] Nuraeni, T. (2011). Perhitungan Ulang Sistem Pengkondisian Udara pada Gerbong Kereta Api Penumpang Eksekutif Malam (KA Gajayana). Digital Library ITS.

[7] PT. INKA. (2010). Kereta Berpenggerak. Diakses 15 Juli 2014, dari INKA:http://www.inka.co.id/?page_id=44

[8] R. Tilley, A. (2002). The Measure of Man and Woman: Human Factors in Design. New York: Henry Dreyfuss Associates.

[9] Iqbal, M. [s.a.]. Desain Eksterior dan Interior Trem sebagai Sarana Transportasi Kota Solo dengan Konsep Aman, Nyaman, dan Ikon Solo Bertema Ekletik. Digital Library ITS.

[10] Kurniawan, A. [s.a.]. Desain Eksterior dan Interior KRD Bandara Juanda Surabaya. Digital Library ITS.

[11] Kusuma, P.A. [s.a.]. Desain Interior Trailer Car Kereta Rel Diesel Elektrik Prambanan Express.. Digital Library ITS.
[12] Tristiyono, B. (2009). DESAIN INTERIOR KERETA API KELAS EKSEKUTIF GENERASI TERBARU DENGAN KONSEP MODULAR. Digital Library ITS.

[13] Widiastuti, E. (2011). Penumpang K.A. Prameks Dibatasi 150 Orang per Gerbong. Dipetik June 15, 2014 dari Solopos: http://www.solopos.com/2011/09/19/penumpangka-pramkes-dibatasi-150-oranggerbong-116203

[14] Wikimedia Foundation. (2003). Kereta Api Prambanan Ekspress. Dipetik July 15, 2015 dari Wikipedia: https://id.wikipedia.org/wiki/Kereta_api_Prambanan_Ekspr es

[15] Wikimedia Foundation. (2003). Kereta Penumpang. Dipetik July 14, 2015 dari Wikipedia: https://id.wikipedia.org/wiki/Kereta_penumpang 